\title{
UNILATERAL NOTCHING OF THE RIBS IN CYANOTIC HEART DISEASE
}

\author{
BY

\section{S. SHAPIRO AND V. SCHRIRE} \\ From the Cardiac Clinic, Groote Schuur Hospital, Cape Town, and the C.S.I.R. Cardiovascular-Pulmonary Research \\ Group, Department of Medicine, University of Cape Town, South Africa
}

Received January 30, 1964

Until 1948 notching of the ribs was considered to be pathognomonic of coarctation of the aorta. Batchelder and Williams (1948), however, drew attention to unilateral notching of the ribs in a patient with tetralogy of Fallot. Unilateral notching is rare, but can occur on the right side when the coarctation is proximal to, or includes, the left subclavian artery (Bayley and Holoubek, 1940; Campbell and Baylis, 1956). It has since been described also in a number of other conditions (Batchelder and Williams, 1948; Holt and Wright, 1948; Reynolds, 1950; Takaro and Clagett, 1951; McCord and Bavendam, 1952; Kent, 1953; Lowe, 1953 and Campbell, 1958), cyanotic heart disease being by far the commonest. This paper reports three further cases.

\section{CASE Reports}

Case 1. G.S., a youth of 19, was first seen at the age of 7 with a history of cyanosis, severe effort intolerance, and squatting since birth. The physical signs and angiocardiograms were those of pulmonary atresia. Chest radiography showed no rib notching (Fig. 1A). A few months later, he had a severe cyanotic attack and collapsed in the street, and shortly thereafter a Blalock-Taussig anastomosis was performed. From that time he improved remarkably and was virtually asymptomatic, apart from mild effort dyspnœea. A distant continuous murmur was audible in the second left intercostal space, an aortic ejection click was present, and there were no cardiac murmurs. Chest radiographs showed a diffuse feathery appearance of the lungs and the development of notching on the fifth, sixth, and seventh ribs on the left (Fig. 1B). Angiocardiography showed a grossly dilated aorta, a functioning left subclavian-pulmonary artery anastomosis, and dilated and tortuous left intercostal arteries which were clearly related to the notched ribs (Fig. 2). The lungs filled shortly after the aorta and intercostal arteries had filled.

Case 2. W.K., a woman of 19, gave a history of cyanosis, severe effort intolerance, and squatting since birth. At 9 years of age Fallot's tetralogy had been diagnosed and pulmonary valvotomy performed without benefit. She was now only able to walk a short distance and was intensely cyanosed. The chest radiograph showed pulmonary oligæmia and notching of the third, fourth, fifth, and sixth ribs on the left (Fig. 3), which had developed since surgery. Angiocardiography showed tortuous and dilated intercostal arteries associated with the notches. The feathery vascular appearance in the lungs suggested a collateral blood supply. The subclavian arteries were normal (Fig. 4). Severe infundibular stenosis with Fallot's tetralogy was confirmed.

In view of the above findings, the radiographs and angiocardiograms of 12 patients with Fallot's tetralogy, who had undergone either a Blalock-Taussig operation or a pulmonary valvotomy, or both, were examined.

Case 3. J. B., a youth of 16 years, was first seen at the age of 5 years with a history of cyanosis, squatting, and intolerance of effort since birth. The tetralogy of Fallot was diagnosed and a BlalockTaussig operation performed with much improvement. A chest radiograph film 11 years later showed notching of the fourth rib on the left. There was atrophy of the fifth rib due to the operation (Fig. 5). 

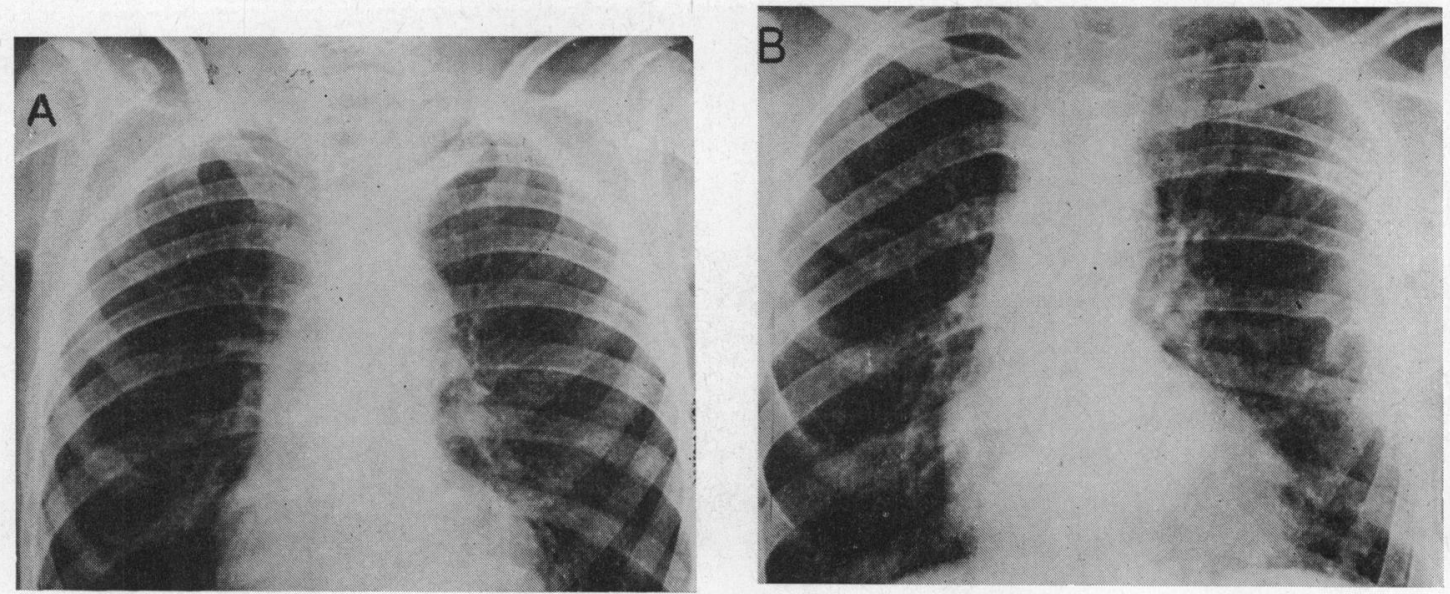

FIG. 1.-Chest radiographs taken (A) pre-operatively in 1951 and (B) 11 years after a Blalock-Taussig operation. Notching has developed in the fifth, sixth, and seventh ribs on the left. The lung fields show a diffuse feathery appearance. (Case 1.)

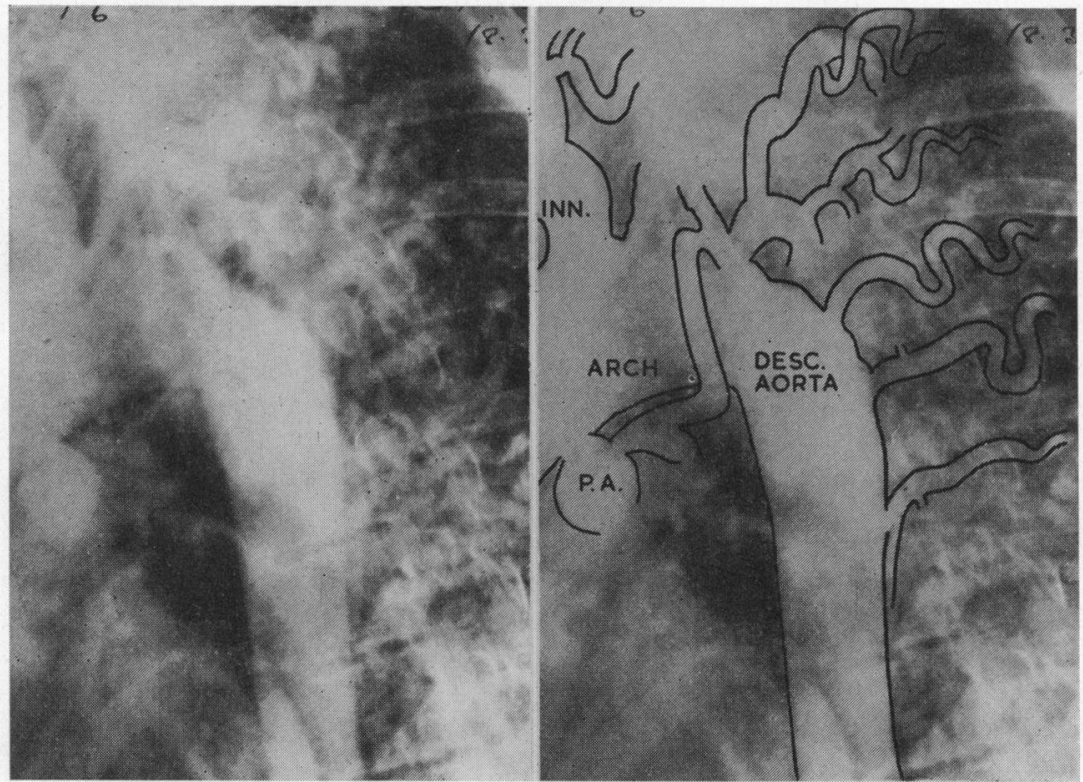

FIG. 2.-An angiocardiogram taken in the left anterior oblique view. The aorta is grossly dilated. The left subclavian-left pulmonary artery anastomosis can be seen below the arch of the aorta. The left intercostal arteries are dilated and tortuous and clearly related to the notched ribs. (Case 1.)

\section{Discussion}

Unilateral notching of the ribs can be divided into three groups:

(1) Coarctation of the aorta proximal to, or including, the left subclavian artery (Bayley and Holoubek, 1940; Campbell and Baylis, 1956).

(2) Cyanotic heart disease. (a) With a history of previous surgical intervention (Kent, 1953; Campbell, 1958); (b) without a history of surgical intervention (Batchelder and Williams, 1948; Reynolds, 1950; Lowe, 1953; Campbell, 1958). 


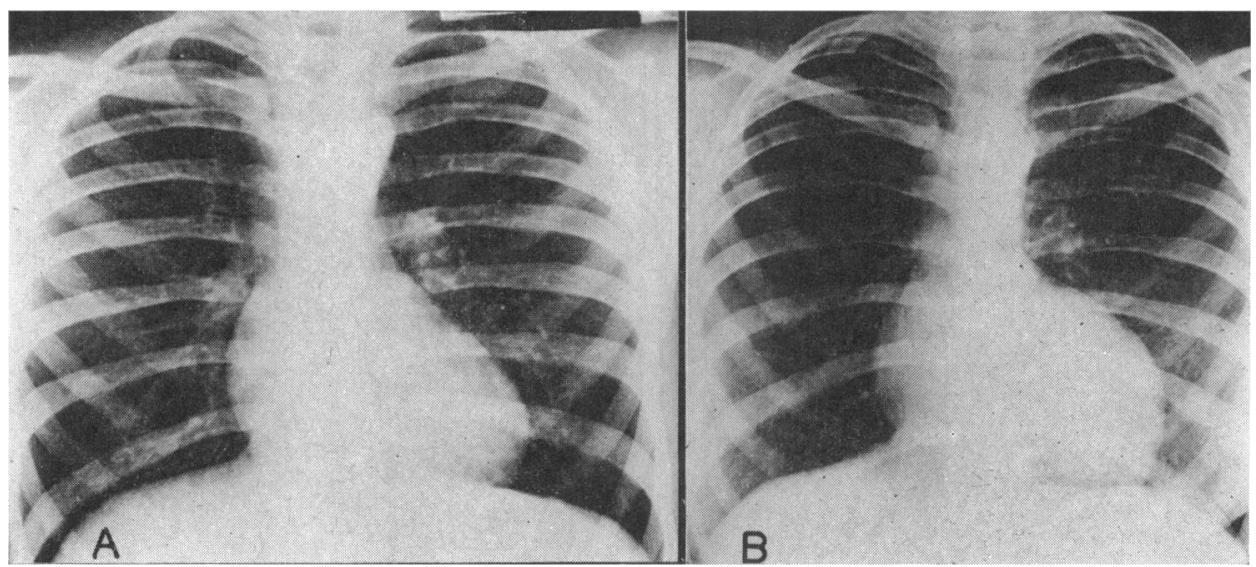

FIG. 3.-Chest radiograph taken (A) pre-operatively in 1953 and (B) 10 years after a pulmonary valvotomy. Notching of the third, fourth, fifth, and sixth ribs on the left, has developed. The lung fields are oligæmic. (Case 2.)

(3) Miscellaneous conditions: neurofibromatosis of the intercostal nerves (Holt and Wright, 1948); vascular malformations of the thoracic wall (Takaro and Clagett, 1951); obstruction of the superior vena cava with the development of collateral channels to the inferior vena cava via the intercostal veins (McCord and Bavendam, 1952); coincidentally in tabo-paresis (McCord and Bavendam, 1952).

By far the majority of cases are associated with cyanotic heart disease and most often notching appears after surgical intervention. Campbell (1958) has suggested that the intercostal arteries

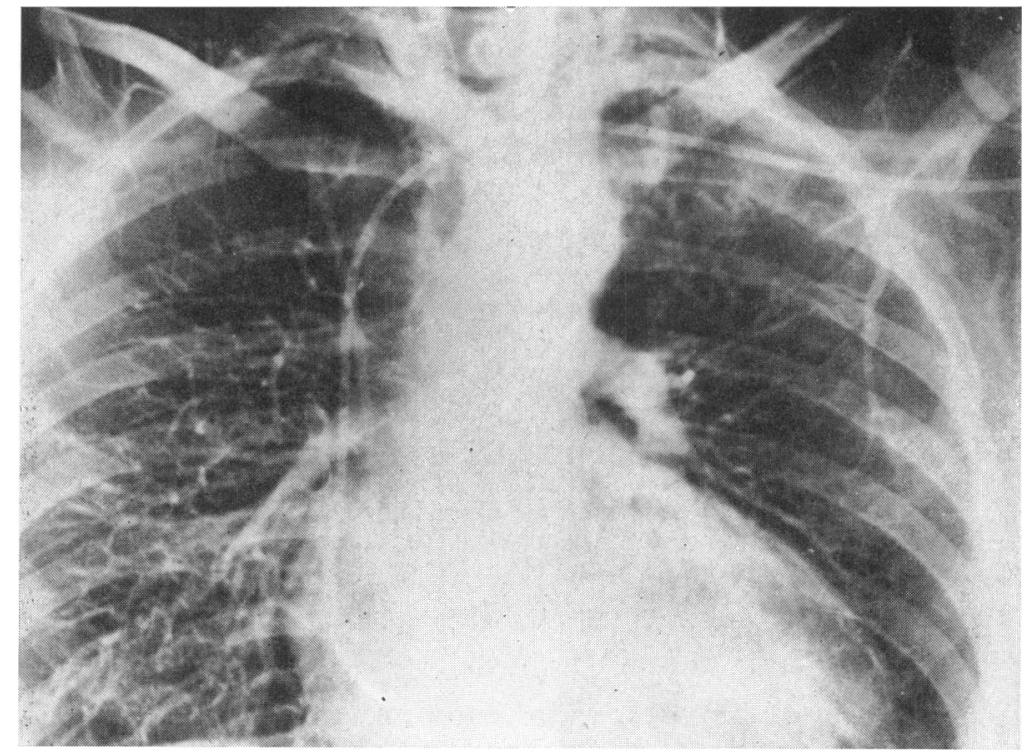

FIG. 4.-An angiocardiogram taken in the postero-arterior view with the catheter in the right ventricle. On the left, tortuous and dilated intercostal arteries are associated with the notched ribs. Both the aorta and the pulmonary artery have filled. The feathery vascular appearance in the lungs suggests a collateral blood supply. The subclavian arteries are normal, but the branches from the left axillary artery are very enlarged. (Case 2.) 


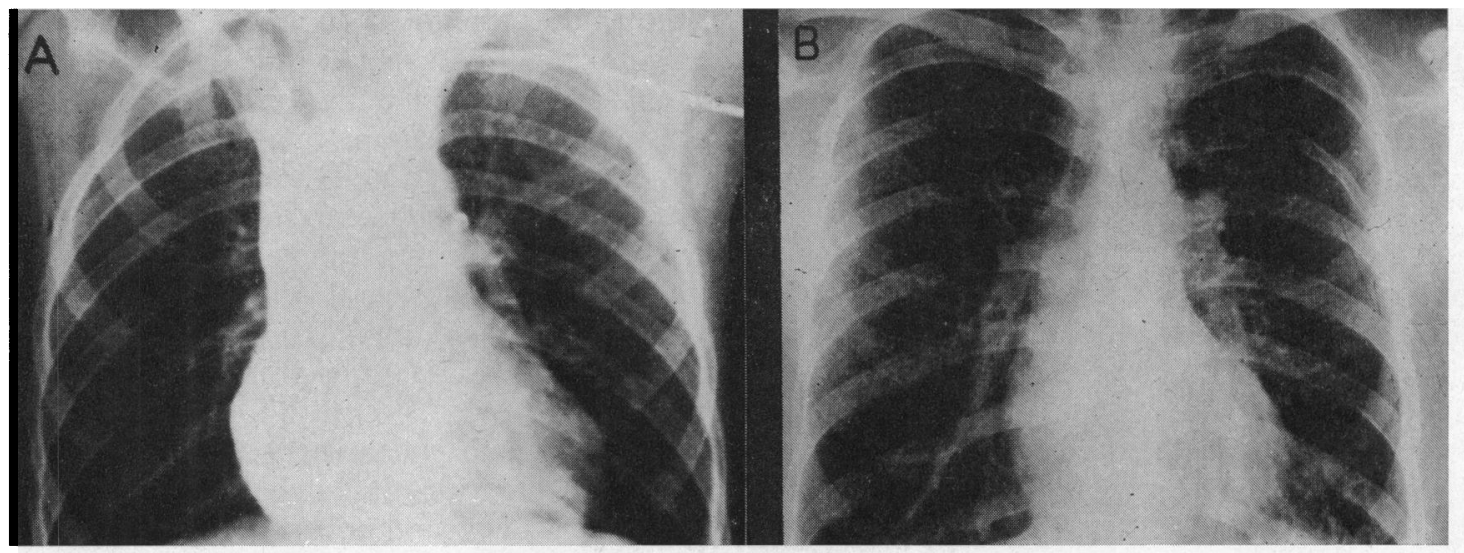

FIG. 5.-(A) A pre-operative angiocardiogram in the postero-anterior view in 1952, and (B) a chest radiograph taken 11 years after a Blalock-Taussig operation. Notching of the fourth left rib has developed. (Case 3.)

dilate as part of the development of a collateral blood supply to the arm following division of the subclavian artery. The detailed anatomy of such a supply has been studied in a patient whose subclavian artery was sectioned in the treatment of a syphilitic aneurysm of the axillary artery (Atkins and Joseph, 1956). The main collateral routes ran via the suprascapular, acromio-thoracic, and upper intercostal arteries. There were also collateral branches from the first part of the subclavian artery to the apex of the lung.

However, this situation is not quite analogous, since the Blalock-Taussig procedure usually implies division of all the branches of the first part of the subclavian artery; collateral routes then depend on branches from the aorta, carotid artery, and arteries from the opposite side of the body. One possible route could run via aortic intercostals, to anterior intercostals, to the internal mammary artery, to anastomoses in the chest wall with the superior thoracic, lateral thoracic, and subscapular arteries and thence to the axillary artery (Campbell, 1958). Presumably the volume of blood carried by this route may sometimes be so large that notching of the ribs occurs.

Collateral blood supply to the arm cannot be the entire explanation since cases have been reported where notching occurred in the absence of obstruction to the subclavian artery (Batchelder and Williams, 1948; Reynolds, 1950; Lowe, 1953; Campbell, 1958). If the histories of such cases are examined, preceding disease in the lung or pleura on the affected side has sometimes been present (Table).

In the three patients reported here, two had a Blalock-Taussig operation, and one had, in effect,

TABLE

Reported Patients With Unilateral Rib Notching who have not Undergone Surgery

\begin{tabular}{|c|c|c|c|c|}
\hline \multicolumn{3}{|c|}{ Author } & Diagnosis & Comments \\
\hline \multicolumn{3}{|c|}{ Batchelder and Williams (1948) } & Fallot's tetralogy & Cystic changes in the apex of the left lung; \\
\hline Reynolds (1950) . & . & .. & $\begin{array}{l}\text { Ebstein's disease; atrial septal } \\
\text { defect; right-to-left shunt }\end{array}$ & $\begin{array}{l}\text { No history of preceding pulmonary or pleural } \\
\text { pathology }\end{array}$ \\
\hline Lowe (1953) & $\cdots$ & .. & Fallot's tetralogy & $\begin{array}{l}\text { Respiratory infection with pleural effusion } \\
20 \text { years previously; cyanosis and effort } \\
\text { tolerance improved thereafter }\end{array}$ \\
\hline Campbell (1958) . & $\cdots$ & . & $\begin{array}{l}\text { Pulmonary atresia; right-sided } \\
\text { aorta }\end{array}$ & $\begin{array}{l}\text { Notching on the right; no history of preceding } \\
\text { pleural or pulmonary pathology }\end{array}$ \\
\hline
\end{tabular}


simply undergone thoracotomy: in the latter case, the angiocardiograms showed a normal subclavian artery. To our knowledge, this is the first time unilateral notching has been reported after thoracotomy alone. It seems likely that if a means of vascular communication through pleural adhesions is present, either as part of a disease process or following operation, then a collateral blood supply can flow into the lungs from the intercostal arteries, and notch the ribs.

There is other evidence to suggest that systemic vessels can form a collateral supply to the lungs, and Barrett and Daley (1949) have pointed out that when artificial pneumothorax is induced in the treatment of tuberculosis, vascular supply to the cavity can occur via pleural adhesions. Most of the cases of unilateral rib notching occur after a Blalock-Taussig operation. This is not surprising since such an operation acts as a double stimulus to increased intercostal flow by promoting collateral flow both to the arm and to the lung.

It is a curious fact that even when an attempt to anastomose the subclavian artery to the pulmonary artery fails, patients sometimes benefit (Barrett and Daley, 1949; Monod, Kateb, and Vandooren, 1950; Kent, 1953). This is probably due to the development of pleural adhesions and collateral systemic flow into the lungs via both intercostal and bronchial arteries. The idea of promoting collateral intercostal blood supply to the lung has formed the basis for an operation in which part of the parietal pleura is stripped and asbestos powder is introduced into the pleural cavity (Barrett and Daley, 1949). With the development of more physiological operations this procedure has fallen into disuse. There are still times when total correction or satisfactory anastomosis are not feasible. Under these circumstances ligation of a subclavian artery, together with a deliberate attempt to stimulate pleural adhesions, might improve the blood supply to the lungs.

\section{SUMMARY}

Unilateral notching of the ribs is reported in 3 patients with cyanotic heart disease. The first, a patient with pulmonary atresia, had a Blalock-Taussig operation 12 years previously. The second, a patient with Fallot's tetralogy, had a pulmonary valvotomy 10 years previously. The third, a patient with Fallot's tetralogy, had a Blalock-Taussig operation 11 years previously.

The importance of the development of a collateral blood supply to the arm following division of the subclavian artery, and of the development of collateral channels to the lungs via pleural adhesions has been discussed.

In the Blalock-Taussig operation, both mechanisms may act in unison.

\section{REFERENCES}

Atkins, H. J. B., and Joseph, J. (1956). The collateral circulation following ligation of the third part of the subclavian artery. Guy's Hosp. Rep., 104, 380.

Barrett, N. R., and Daley, R. (1949). A method of increasing the lung blood supply in cyanotic congenital heart disease. Brit. med. J., 1, 699.

Batchelder, P., and Williams, R. J. (1948). Notching of ribs without coarctation. Radiology, 51, 826. Bayley, R. H., and Holoubek, J. E. (1940). Coarctation of the aorta at or above the origin of the left subclavian artery.
Brit. Heart J., 2, 208. Campbell, M. (1958), Unilateral rib-notching from the collateral circulation after division of the subclavian artery.
Brit. Heart J., 20, 253 .

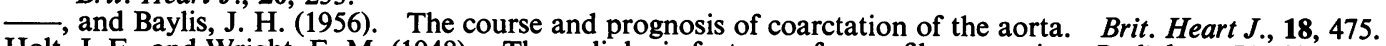

Holt, J. F., and Wright, E. M. (1948). The radiologic features of neurofibromatosis. Radiology, 51, 647.

Kent, J. V. (1953). The development of rib notching after surgical intervention in congenital heart disease. Brit. J. Radiol., 26, 346.

Lowe, J. B. (1953). The angiocardiogram in Fallot's tetralogy. Brit. Heart J., 15, 319.

McCord, M., and Bavendam, F. A. (1952). Unusual cases of rib notching. Amer. J. Roentgenol., $67,405$.

Monod, O. W. F., Kateb, E. H., and Vandooren, M. F. (1950). Considerable improvement following exploratory thoracotomy in two cases of tetralogy of Fallot. J. thorac. Surg., 20, 158.

Reynolds, G. (1950). Ebstein's disease-A case diagnosed clinically. Guy's Hosp. Rep., 99, 276.

Takaro, T., and Clagett, O. T. (1951). Cavernous hemangioma of the thoracic wall associated with clinical evidence of arteriovenous fistulas. J. thorac. Surg., 21, 444. 